\title{
Soldagem de Topo por Fricção entre a Liga de Alumínio 6351-T6 e o Aço SAE 1020 Assistida por Indução Eletromagnética
}

\author{
Sheron Stephany Tavares ${ }^{1}$, Alexandre Queiroz Bracarense ${ }^{1}$ \\ 1 Universidade Federal de Minas Gerais - UFMG, Departamento de Engenharia Mecânica, Laboratório de Robótica, Soldagem \\ e Simulação - LRSS, Belo Horizonte, MG, Brasil.
}

Recebido: 08 Fev., 2017

Aceito: 26 Abr., 2017

E-mail(s): sheron_tavares@yahoo.com.br (SST), bracarense@ufmg.br (AQB)
Este é um artigo publicado em acesso aberto (Open Access) sob a licença Creative Commons Attribution Non-Commercial, que permite uso, distribuição e reprodução em qualquer meio, sem restriçōes desde que sem fins comerciais e que 0 trabalho original seja corretamente citado.
Resumo: A soldagem por friç̧ão tem tomado um rumo muito interessante. O presente trabalho teve como objetivo avaliar o efeito do preaquecimento na soldagem por fricção convencional entre a liga de alumínio AA 6351-T6 e o aço SAE 1020. Uma furadeira de coluna foi adaptada para produzir as juntas dissimilares. As soldagens foram realizadas em duas condições: sem preaquecimento e com preaquecimento de $350^{\circ} \mathrm{C}$ induzido eletromagneticamente. Os parâmetros de soldagem, com exceção do tempo de fricção foram mantidos constantes, pois uma nova variável foi inserida ao processo, a temperatura de preaquecimento. A caracterização microestrutural da solda foi realizada por MO e MEV. A resistência mecânica foi avaliada pelos ensaios de microdureza Vickers e tração. Os resultados mostraram que a utilização do preaquecimento diminui o tempo total de processo pela metade. A análise via MEV-EDX evidenciou que houve interdifusão entre o ferro e o alumínio. Para as duas condições de soldagem, a ruptura ocorreu na interface de ligação. A resistência mecânica das soldas sem preaquecimento foi da ordem de $134 \mathrm{MPa}$ e $113 \mathrm{MPa}$ para as soldas com preaquecimento.

Palavras-chave: Soldagem por fricção; Materiais dissimilares; Indução eletromagnética.

\section{Friction Butt Welding between 6351-T6 Aluminum Alloy and SAE 1020 Steel Assisted by Electromagnetic Induction}

Abstract: Friction welding has become interesting in terms of its application. In this context, this paper aimed to evaluate the effect of preheating the conventional friction butt welding between the aluminum alloy AA 6351-T6 and low-carbon steel SAE 1020. An adapted and instrumented drill was applied to make dissimilar joints. Welding was done under two conditions: without preheating and with electromagnetically induced preheating to about $350^{\circ} \mathrm{C}$. The welding parameters, with the exception of friction time, were kept constant for both conditions because a new variable was introduced to the process, the preheating temperature. The welding characterisation was analyzed by optical microscopy (OM) and scanning electron microscopy (SEM). Vickers microhardness and traction testing were used to evaluate the welding mechanical strength. The results obtained shown that preheating application decreases by half the total time of the process. The SEM-EDX analysis showed that there was interdiffusion between iron and aluminum. For both welding conditions, the rupture occurred on the bonding interface of the specimens. The mechanical strength of the welds without preheating was of the order of $134 \mathrm{MPa}$ and $113 \mathrm{MPa}$ for welds with preheating.

Key-words: Friction welding; Dissimilar materials; Electromagnetic induction.

\section{Introdução}

A soldagem de materiais dissimilares como o alumínio e o aço desperta grande interesse na indústria do transporte. A busca por materiais mais leves com intuito de reduzir o peso nas estruturas veiculares é alvo de frequente pesquisa, em especial na indústria automobilística [1]. No entanto, a união desses materiais é um grande desafio, pois eles possuem propriedades mecânicas e térmicas muito distintas, e quando soldados pelos processos de fusão formam quantidade apreciável de compostos intermetálicos frágeis (CIM), os quais reduzem a resistência da solda [2,3].

Nesse cenário, uma alternativa para soldagem de materiais dissimilares são os métodos de união no estado sólido. Esses processos são caracterizados por ocorrerem em temperaturas mais baixas, sem que haja fusão dos metais de base, logo, a formação de fases intermetálicas é reduzida [4]. Dentre os processos no estado sólido, os métodos de soldagem por fricção são os que têm sido mais utilizados na união de dissimilares [5], como a união de alumínio e aço. 
Soldagem de Topo por Fricção entre a Liga de Alumínio 6351-T6 e o Aço SAE 1020 Assistida por Indução Eletromagnética

Dentre os métodos de soldagem por friç̧ão, na soldagem por fricção convencional, o aquecimento responsável pela união é gerado mecanicamente por duas superfícies em contato. Uma das superfícies é mantida fixa, enquanto a outra se encontra em rotação. A peça em rotação se aproxima da peça parada, e assim é iniciado atrito entre elas. As superfícies aquecem e se deformam devido ao atrito e a pressão. Um colar de rebarba é observado no final do processo, proveniente do escoamento dos materiais durante a soldagem [6].

Na soldagem por fricção convencional os parâmetros de soldagem são: velocidade de rotação, tempo de fricção, pressão de fricção, tempo de forjamento e a pressão de forjamento. Uma nova variável foi colocada ao processo, a temperatura de preaquecimento. Então, esse trabalho teve como principal objetivo avaliar o efeito do preaquecimento por indução eletromagnética nos parâmetros de soldagem, especificamente, no tempo de fricção e nas propriedades mecânicas e metalúrgicas da interface de ligação.

\section{Materiais e Métodos}

Os metais de base utilizados nesse trabalho foram barras cilíndricas da liga de alumínio 6351-T6 e o aço baixo teor de carbono SAE 1020 ambos com diâmetro de 12,7 mm. O comprimento da liga de alumínio foi de $65 \mathrm{~mm}$ e do aço $50 \mathrm{~mm}$. Na Tabela 1 é mostrada a composição química dos materiais de base de acordo com os fabricantes, Companhia Brasileira de Alumínio e ArcelorMittal.

Tabela 1. Composição química dos materiais (\% em peso).

\begin{tabular}{|c|c|c|c|c|c|c|c|c|c|}
\hline \multirow{2}{*}{ AA 6351-T6 } & $\% \mathbf{S i}$ & $\% \mathrm{Cu}$ & $\% M n$ & $\% \mathbf{M g}$ & $\% Z n$ & $\% \mathrm{Ti}$ & $\% \mathrm{Fe}$ & \%Outros & $\% A I$ \\
\hline & $0,70-1,30$ & 0,1 & $0,40-0,80$ & $0,40-0,80$ & 0,20 & 0,20 & 0,50 & 0,15 & Restante \\
\hline \multirow{2}{*}{ SAE 1020} & \multicolumn{2}{|c|}{$\% S i$} & \multicolumn{2}{|c|}{$\% C$} & \multicolumn{2}{|c|}{$\% M n$} & $\% S$ & $\% \mathrm{P}$ & \%Мo \\
\hline & \multicolumn{2}{|c|}{0,06} & \multicolumn{2}{|c|}{0,19} & \multicolumn{2}{|c|}{0,49} & 0,013 & 0,011 & 0,0031 \\
\hline
\end{tabular}

O equipamento de soldagem utilizado nessa pesquisa foi uma furadeira de coluna, cuja velocidade de rotação máxima é de 1100 rpm e a potência do motor é de $560 \mathrm{~W}$. A força de compressão necessária à soldagem foi aplicada nos corpos de prova de maneira gradual, por meio de anilhas com massas calibradas de $5 \mathrm{~kg}$. Essas cargas foram colocadas em uma haste de aço com um metro de comprimento, a qual foi acoplada na alavanca de aproximação da furadeira. A leitura da força de compressão e do torque durante a soldagem foi monitorada através de uma célula de carga conectada a um sistema de aquisição de dados. Na Figura 1 é apresentada a as adaptações realizadas na furadeira.

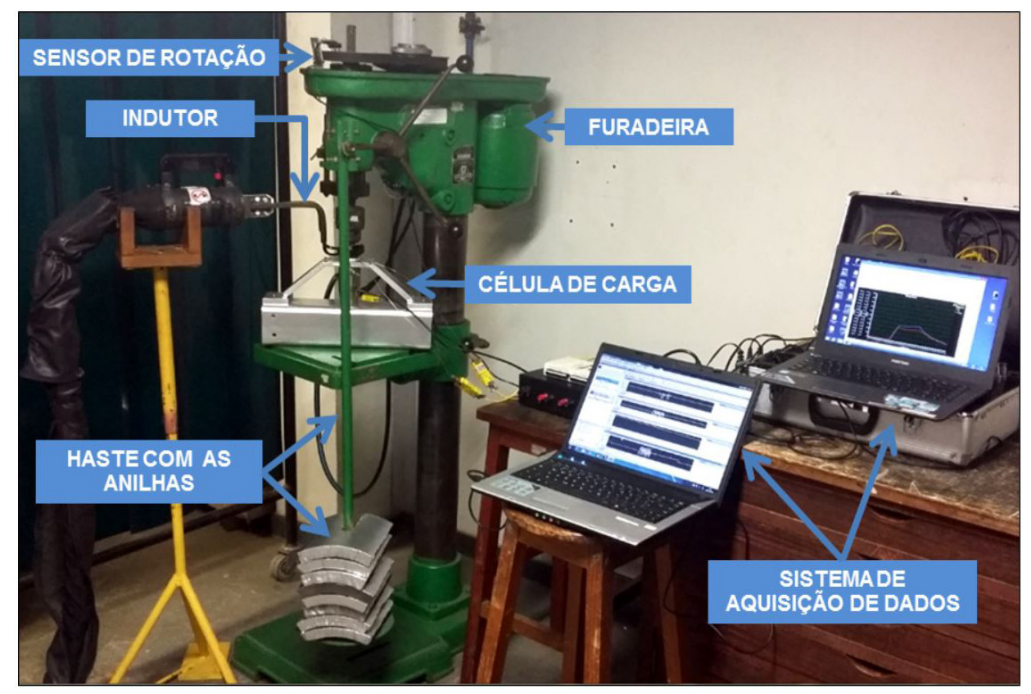

Figura 1. Furadeira de Coluna especialmente adaptada para o trabalho. 
Para a furadeira utilizada, a força é aplicada no corpo de prova através de um braço de alavanca que transfere a carga para a cremalheira que coordena o movimento de descida do cabeçote. $O$ fator de amplificação do braço para a cremalheira é de aproximadamente 7:1. Isso significa que quando uma carga de $5 \mathrm{kgf}$ é inserida na haste, uma massa de 35 kgf é transferida aos corpos de prova. Na Figura 2 é mostrado o esquema de amplificação da carga.

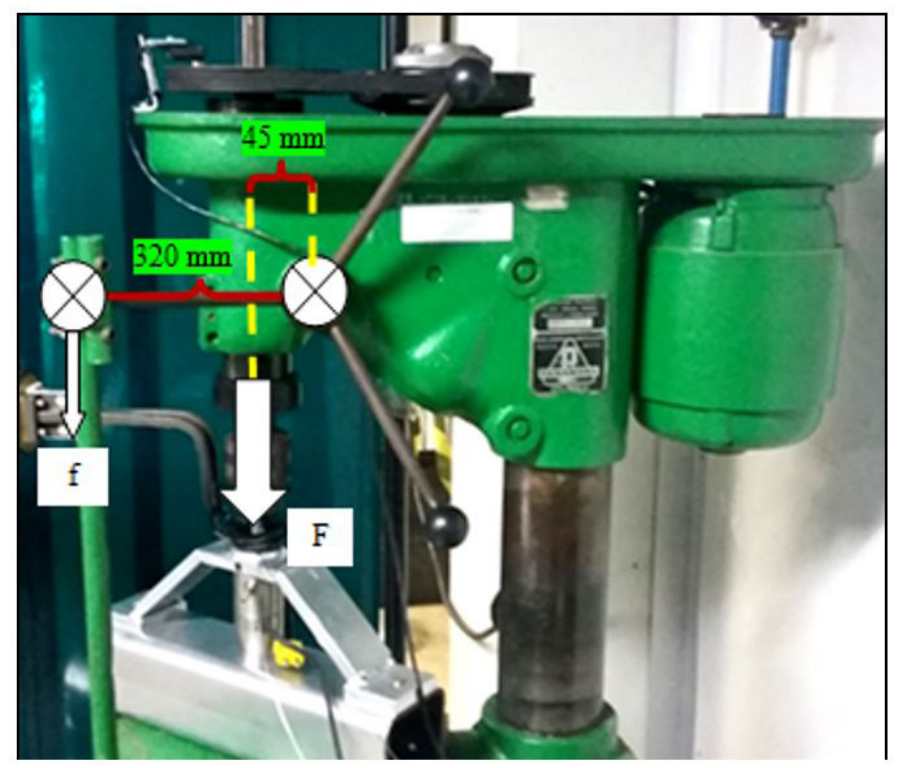

Figura 2. Representação esquemática da aplicação de carga na furadeira- (f) é a força aplicada na haste e (F) é a força transmitida na célula de carga e para os corpos de prova.

Os parâmetros de soldagem utilizados estão apresentados na Tabela 2. As soldagens foram divididas em dois estágios, o de friç̧ão e o de forjamento. As cargas foram aplicadas durante o tempo de fricção através da haste apresentada na Figura 1. 0 corpo de prova de alumínio foi acoplado no mandril da furadeira, sendo rotacionado durante a soldagem, enquanto o corpo de prova de aço foi fixado na célula de carga. A temperatura de preaquecimento foi de $350^{\circ} \mathrm{C}$ e simultaneamente ao preaquecimento, os corpos de prova foram colocados em atrito sem aplicação das cargas.

Tabela 2. Parâmetros de soldagem.

\begin{tabular}{|c|c|c|c|c|c|c|c|}
\hline \multirow{2}{*}{ Soldas } & \multirow{2}{*}{$\begin{array}{c}\text { Velocidade } \\
\text { de rotação } \\
\text { (RPM) }\end{array}$} & \multicolumn{2}{|c|}{ *Tempo de fricção (s) } & \multirow{2}{*}{$\begin{array}{l}\text { **Pressão } \\
\text { de fricção } \\
\text { (MPa) }\end{array}$} & \multirow{2}{*}{$\begin{array}{l}\text { Tempo de } \\
\text { forjamento } \\
\text { (s) }\end{array}$} & \multirow{2}{*}{$\begin{array}{c}\text { Pressão de } \\
\text { forjamento } \\
\text { (MPa) }\end{array}$} & \multirow{2}{*}{$\begin{array}{l}{ }^{* * *} \text { Tem- } \\
\text { peratura } \\
\text { inicial }\left({ }^{\circ} \mathrm{C}\right)\end{array}$} \\
\hline & & Sem carga & Com carga & & & & \\
\hline Sem preaquecimento & 1100 & 30 & $\approx 26$ & 22 & 7 & 22 & 25 \\
\hline Com preaquecimento & 1100 & 7 & $\approx 19$ & 22 & 7 & 22 & 350 \\
\hline
\end{tabular}

* O tempo de fricção é a soma do tempo de atrito sem carga e com carga. O tempo de atrito com carga foi dependente do aplicador de cargas: ** A área de contato entre as barras foi de $126,67 \mathrm{~mm}^{2}$; *** Foram testados diferentes temperaturas de preaquecimento, porém foi possível obter solda quando se empregou a temperatura de $350^{\circ} \mathrm{C}$.

\section{Resultados e Discussão}

\subsection{Monitoramento do torque e da pressão}

Com o auxílio da célula de carga foi possível monitorar em tempo real o torque devido ao atrito e a força de compressão durante a soldagem. As Figuras 3 e 4 mostram o comportamento dessas variáveis para cada combinação de parâmetro utilizado. As setas nos gráficos indicam a aplicação da última carga. 


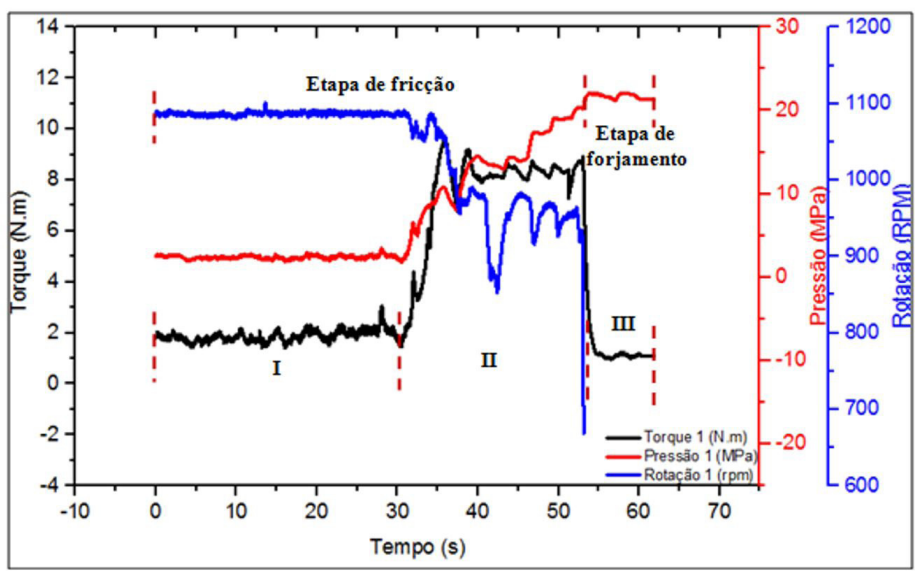

Figura 3. Monitoramento do torque, da pressão e da velocidade de rotação para as soldas sem preaquecimento.

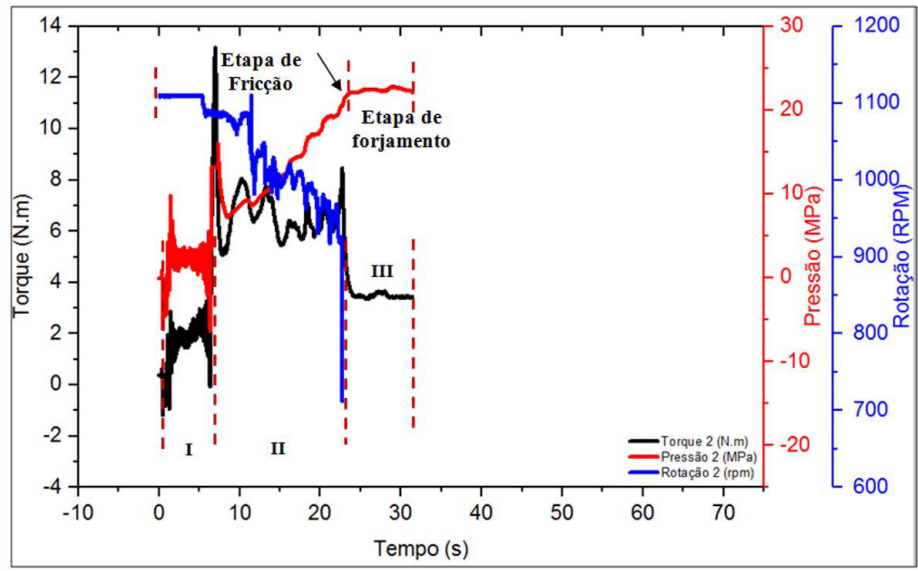

Figura 4. Monitoramento do torque, da pressão e da velocidade de rotação para as soldas com preaquecimento.

A etapa de fricção foi dividida em duas fases: tempo de atrito sem carga e tempo de atrito com carga. No tempo de atrito sem carga, indicado no gráfico pela região I, os corpos de prova ficaram em atrito sem a aplicação das cargas, somente pelo peso da haste de metal. Para as soldas realizadas sem preaquecimento, o tempo de atrito sem a carga foi de 30 segundos ( 0 aos 30 segundos). Para as soldas com preaquecimento, o tempo de atrito sem carga foi de 7 segundos ( 0 aos 7 segundos), intervalo de tempo em que ocorreu o preaquecimento por indução eletromagnética na interface aço-alumínio. Na fase de atrito sem carga, os valores de torque, pressão e rotação mantiveram- se constantes.

A partir dos 30 segundos para as soldas sem preaquecimento e dos 7 segundos para as soldas com preaquecimento, as cargas foram inseridas gradualmente na haste. Esta fase do processo é caracterizada como tempo de atrito com carga e está mostrada no gráfico pela região II. À medida que as cargas foram colocadas na haste, a velocidade de rotação foi reduzida enquanto a pressão e o torque aumentaram. Quando a última carga foi inserida, desligou-se a furadeira, encerrando-se a fase de fricção.

A etapa de forjamento foi iniciada com a interrupção da velocidade de rotação da furadeira e está indicada no gráfico pela região III. O tempo total na etapa de forjamento foi de 7 segundos, nesse intervalo de tempo, os corpos de prova atingiram a pressão máxima de processo enquanto o torque e a velocidade de rotação atingiram seus mínimos valores.

Os gráficos mostram que as soldas realizadas com preaquecimento aconteceram em menor tempo. O tempo total de processo para as soldas com preaquecimento foi de 33 segundos, sendo 7 segundos no tempo de atrito sem carga, 19 segundos no tempo de atrito com carga e 7 segundos no tempo de forjamento. Para as soldas sem 
preaquecimento, o tempo total foi de 63 segundos, sendo 30 segundos no tempo de atrito sem carga, 26 segundos no tempo de atrito com carga e 7 segundos no tempo de forjamento. A aplicação do preaquecimento na interface aço-alumínio reduziu pela metade o tempo total de processo.

\subsection{Análise macrográfica}

A análise visual realizada nas soldas sem preaquecimento e com preaquecimento é mostrada na Figura 5. As rebarbas formadas em cada uma das condições empregadas foram bem semelhantes, evidenciando que houve uma repetibilidade do processo. A rebarba formada sem a aplicação do preaquecimento ficou com aspecto mais arredondo e volumoso em comparação com a rebarba gerada na condição preaquecida.

O tempo de friç̧ão, e consequentemente, o tempo total de processo na soldagem sem preaquecimento foi maior em relação às soldas realizadas com aquecimento, assim sendo, essas soldas ficaram mais tempo expostos ao calor gerado pelo atrito das superfícies. Logo, houve uma maior deformação no comprimento do corpo de prova de alumínio na condição não preaquecida. Em relação ao comprimento inicial, o alumínio reduziu $11 \mathrm{~mm}$ nas soldas obtidas sem aquecimento e $8 \mathrm{~mm}$ nas soldas realizadas com preaquecimento.

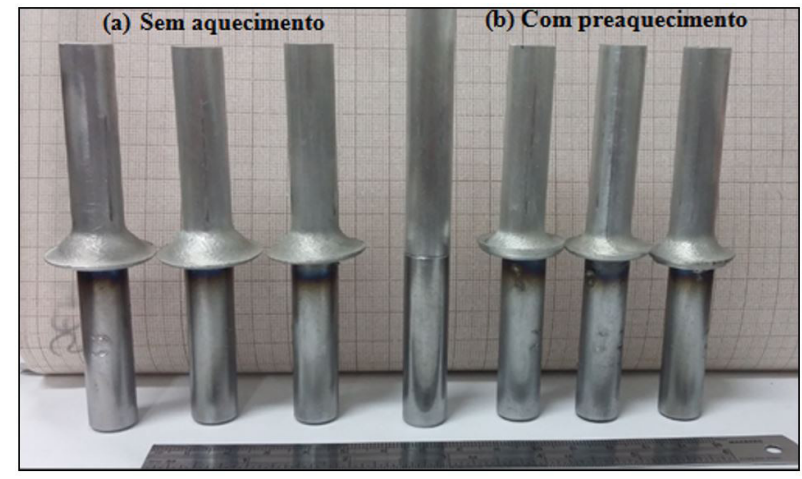

Figura 5. Fotografia dos corpos de prova após a soldagem - (a) sem aquecimento e (b) com aquecimento.

\subsection{Análise micrográfica}

Nas Figuras 6 e 7 são apresentados os perfis micrográficos da interface de ligação.

A zona termicamente afetada em ambos os materiais foi muito pequena, não sendo observada pela técnica de microscopia óptica. Tanto no lado do aço quanto no lado do alumínio não foram observadas mudanças microestruturais adjacentes à região de ligação. A maior parcela de deformação plástica proveniente dos parâmetros de soldagem empregados ocorreu na liga de alumínio, pois este possui menor resistência mecânica em comparação

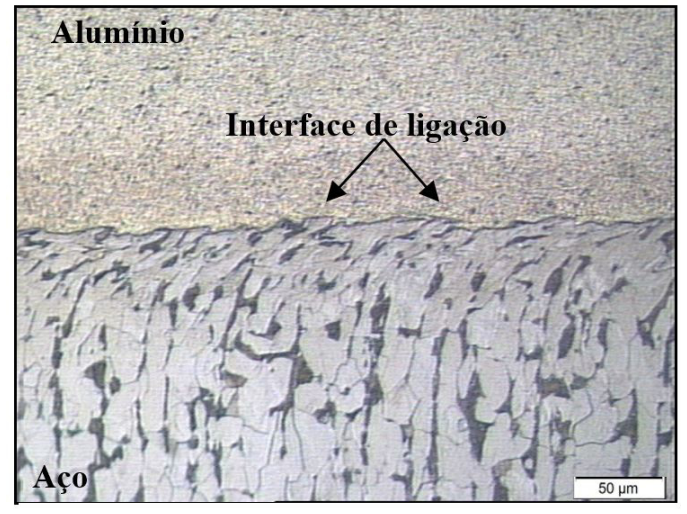

Figura 6. Micrografia da solda sem preaquecimento. 


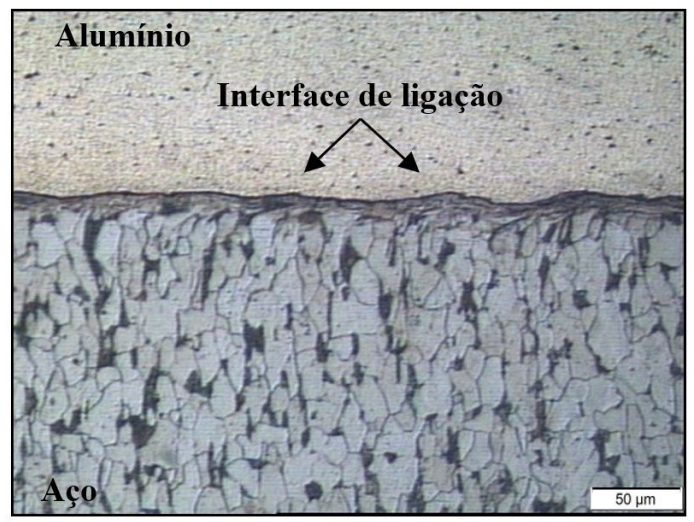

Figura 7. Micrografia da solda com preaquecimento.

com o aço. Contudo, é possível notar que aconteceu uma pequena deformação dos grãos de ferrita e perlita no aço próximo à interface de ligação para as duas condições de soldagem.

\subsection{Análise por microscopia eletrônica de varredura}

A análise da interface de ligação da região central foi realizada através da técnica de varredura de line scan EDX, mostrado nas Figuras 8, 9 e 10, o qual forneceu um entendimento semiquantitativo do processo em função dos parâmetros de soldagem utilizados. Os resultados obtidos pelo line scan evidenciaram que ocorreu interdifusão entre o alumínio e ferro, caracterizando um dos principais mecanismos de ligação na soldagem por fricção, a difusão.

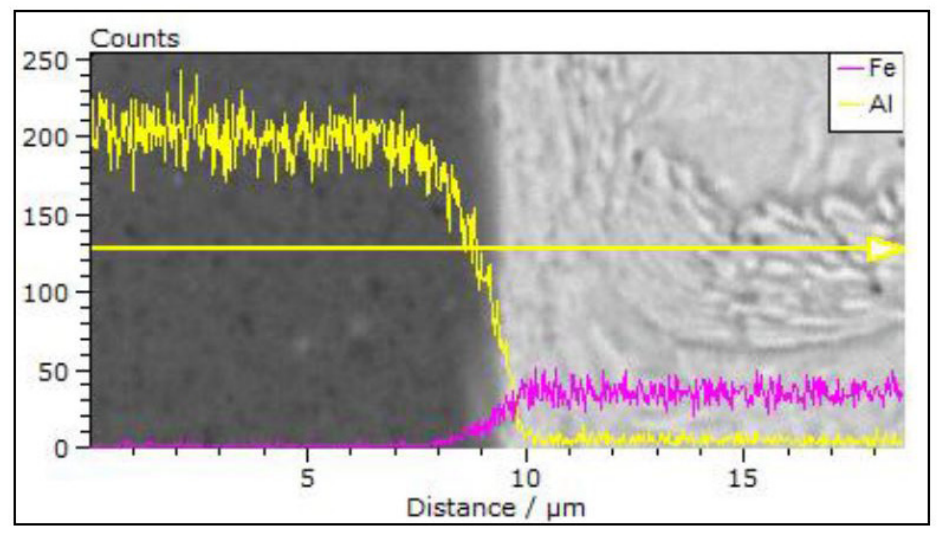

Figura 8. Análise semiquantitativa por EDX das soldas sem preaquecimento mostrando a interdifusão entre o Al e Fe.

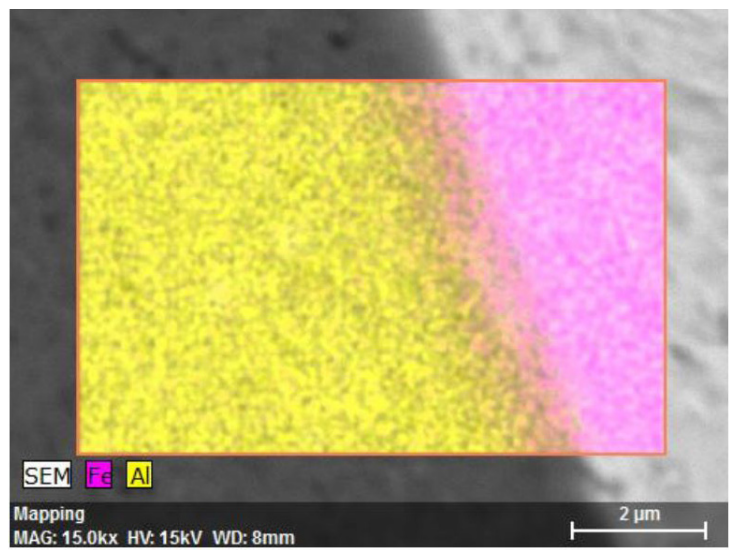

Figura 9. Mapeamento da interdifusão entre o alumínio e o aço para as soldas sem preaquecimento. 


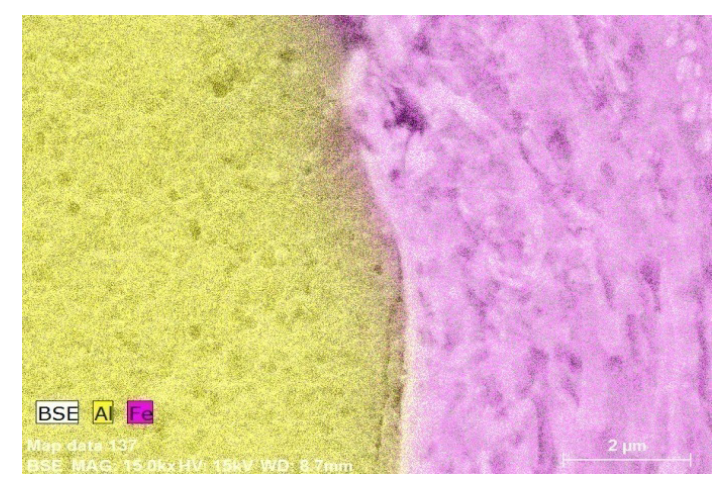

Figura 10. Mapeamento da interdifusão entre o alumínio e o aço para as soldas com preaquecimento.

\subsection{Ensaios mecânicos}

\section{a) Microdureza Vickers}

Os perfis de microdureza foram feitas ao no eixo horizontal da solda, tomando como referência a interface de ligação (IL) alumínio-aço. As medidas foram realizadas a $0,5 \mathrm{~mm}$ e a $2,5 \mathrm{~mm}$ da interface e estão mostradas nas Figuras 11 e 12.

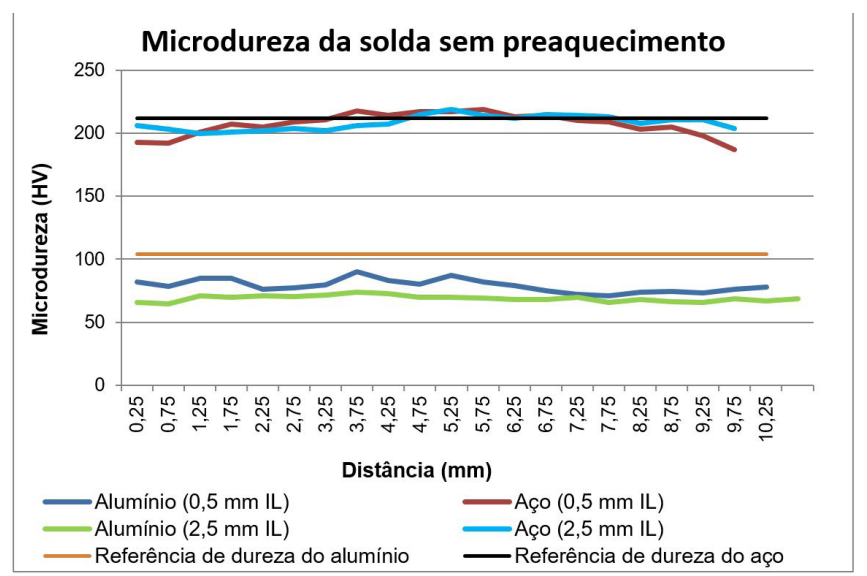

Figura 11. Perfil de microdureza próximos à interface de ligação para as soldas sem preaquecimento.

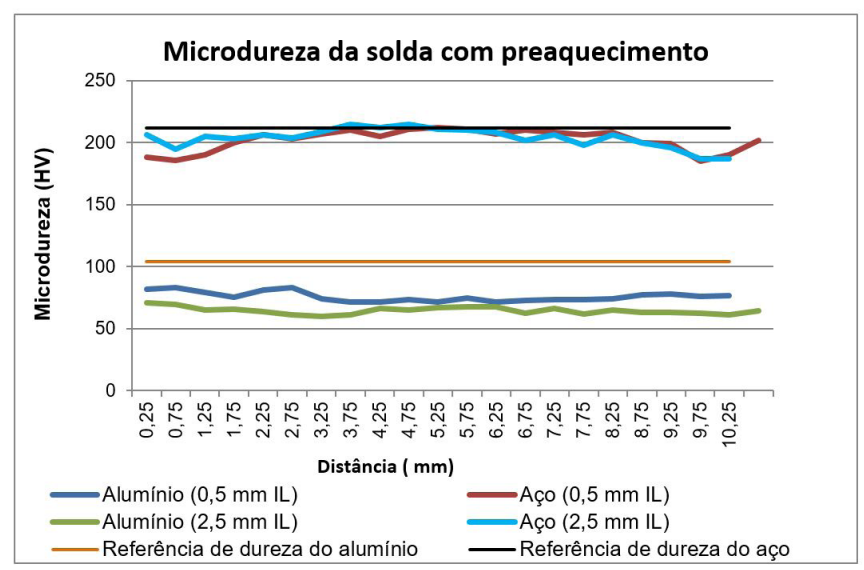

Figura 12. Perfil de microdureza próximos à interface de ligação para as soldas com preaquecimento. 
Soldagem de Topo por Fricção entre a Liga de Alumínio 6351-T6 e o Aço SAE 1020 Assistida por Indução Eletromagnética

Na direção horizontal do alumínio, tomando como referência o valor de 105 HV, que corresponde o valor de dureza do metal base da liga de alumínio 6351-T6, houve uma redução nos valores de microdureza para as duas condições soldadas. Essa perda de dureza se deve ao superenvelhecimento que ocorre em ligas soldadas na condição de envelhecimento completo, que é o caso da liga estudada [7]. De acordo com a literatura, os valores de dureza são sensíveis à entrada de calor, à pressão de fricção e à pressão de forjamento [8]. A redução nos valores de dureza do alumínio na soldagem por fricção tem sido relatada por outros autores $[9,10]$.

Embora tenha ocorrido perda de dureza no alumínio, nas proximidades com a interface de ligação a perda de dureza foi menor, isso se deve a deformação plástica sofrida na liga de alumínio em função dos parâmetros de soldagem empregados. A distância de $0,5 \mathrm{~mm}$ da interface, a microdureza do alumínio para as soldas sem preaquecimento foi de $79 \mathrm{HV}$ e para as soldas preaquecidas $75 \mathrm{HV}$. A 2,5 mm da interface, a dureza da solda à temperatura ambiente foi de $69 \mathrm{HV}$ e para as soldas preaquecidas $65 \mathrm{HV}$.

Na direção horizontal do lado do aço, adotando como padrão a dureza de 212 HV, que é o valor de dureza do metal base do aço SAE 1020 trefilado, nota-se que o perfil de microdureza para as duas condições de soldagem foram semelhantes.

\section{b)Ensaio de Tração}

Os corpos de prova previamente usinados conforme a norma ASTM E8M [11] foram submetidos a ensaio de tração para determinação da resistência mecânica máxima da junta soldada. Foram realizados 9 testes de tração para as amostras sem aquecimento e 7 para as amostras com aquecimento. Nas duas condições de soldagem empregadas, a ruptura dos corpos de prova aconteceu na interface de ligação, como pode ser visto na Figura 13. Na Tabela 3 são apresentados os resultados obtidos no ensaio de tração para as duas condições de soldagem.

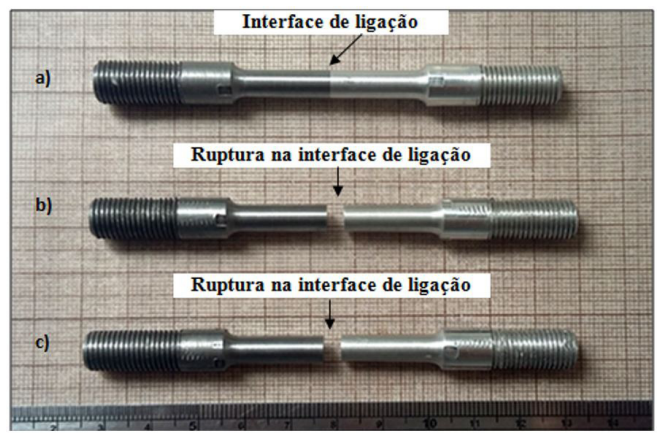

Figura 13. Corpos de prova antes a após o ensaio de tração - (a) antes do ensaio de tração, (b) ruptura na interface de ligação para a solda sem aquecimento e (c) ruptura na interface de ligação para solda com preaquecimento.

Tabela 3. Resultados obtidos nos ensaios de tração.

\begin{tabular}{ccc}
\hline Amostras & $\begin{array}{c}\text { Soldas sem preaquecimento } \boldsymbol{\sigma}_{\mathbf{R}} \\
(\mathbf{M P a})\end{array}$ & $\begin{array}{c}\text { Soldas com preaquecimento } \boldsymbol{\sigma}_{\mathbf{R}} \\
(\mathbf{M P a})\end{array}$ \\
\hline 1 & 144 & 140 \\
\hline 2 & 126 & 132 \\
\hline 3 & 146 & 84 \\
\hline 4 & 122 & 84 \\
\hline 5 & 101 & 124 \\
\hline 6 & 119 & 112 \\
\hline 7 & 130 & 113 \\
\hline 8 & 160 & - \\
\hline 9 & 156 & 113 \\
\hline Média & 134 & $95 \%$ de confiança: 2,477 \\
\hline $\begin{array}{c}\text { Coeficiente } \boldsymbol{t} \text {-student para } \mathbf{n}-\mathbf{1} \text { graus } \\
\text { de liberdade }\end{array}$ & $95 \%$ de confiança: 2,306 & $(113 \pm 54) \mathrm{MPa}$ \\
\hline Resultado de Medição & $(134 \pm 44) \mathrm{MPa}$ & \\
\hline
\end{tabular}


Tomando como referência a menor resistência mecânica do material utilizado no processo, a liga 6351-T6, os parâmetros de soldagem, em especial a pressão de fricção e forjamento e a velocidade de rotação empregada nessa pesquisa foram inferiores aos valores de pressão e rotação utilizados na literatura [9,12], para a mesma liga. Esse fato justifica a ruptura dos corpos de prova ter ocorrido na interface de ligação e não do lado do alumínio como esperado. De acordo com a literatura [13], maiores pressões aumentam o contato íntimo entre as superfícies e, consequentemente, a adesão entre eles. Contudo, o incremento da pressão nesse trabalho causaria instabilidade no processo, principalmente na furadeira, por esse motivo, a pressão não foi aumentada.

Nas Figuras 14, 15, 16 e 17 são apresentadas as superfícies de fratura dos corpos de prova de tração. A superfície de fratura ocorreu na interface de ligação e não houve deformação dos corpos de prova antes da ruptura. Indícios de alumínio foram observados na superfície de fratura dos corpos de prova de aço e foram confirmados através de análises com microscópio eletrônico de varredura. A presença de alumínio na superfície de fratura do aço e a presença de ferro na superfície de fratura do alumínio foram mais pronunciadas nas soldas sem preaquecimento.

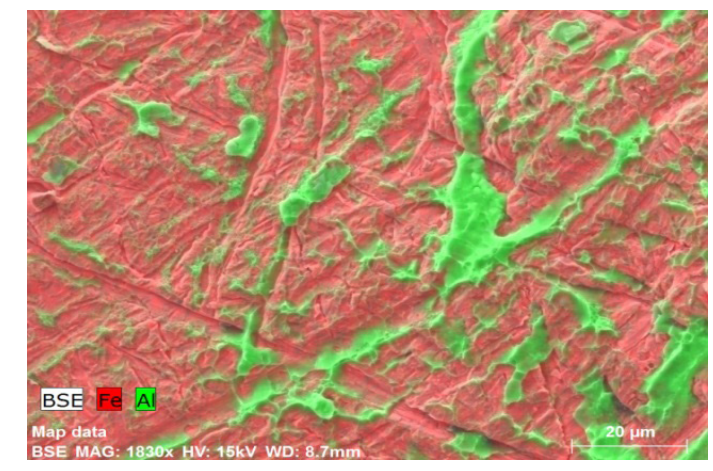

Figura 14. Superfície de fratura do aço. Soldas sem preaquecimento.

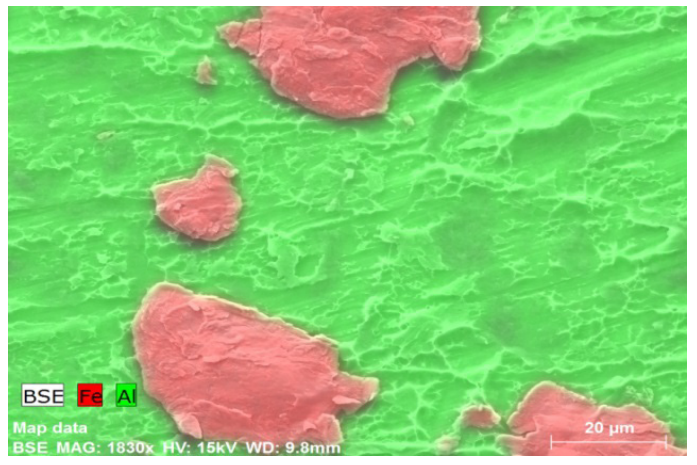

Figura 15. Superfície de fratura do alumínio. Soldas sem preaquecimento.

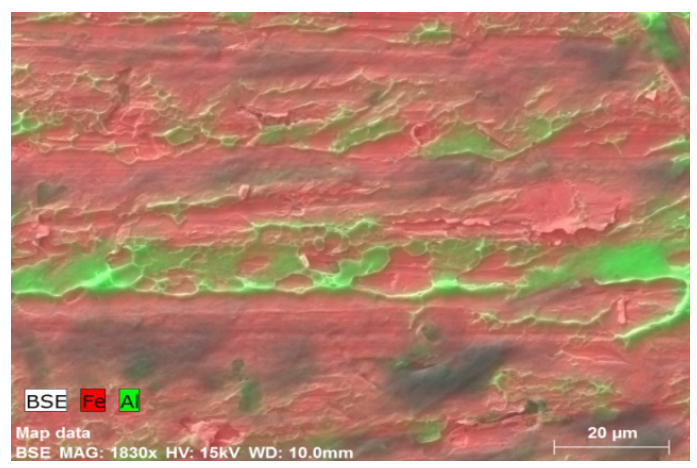

Figura 16. Superfície de fratura do aço. Soldas com preaquecimento. 
Soldagem de Topo por Fricção entre a Liga de Alumínio 6351-T6 e o Aço SAE 1020 Assistida por Indução Eletromagnética

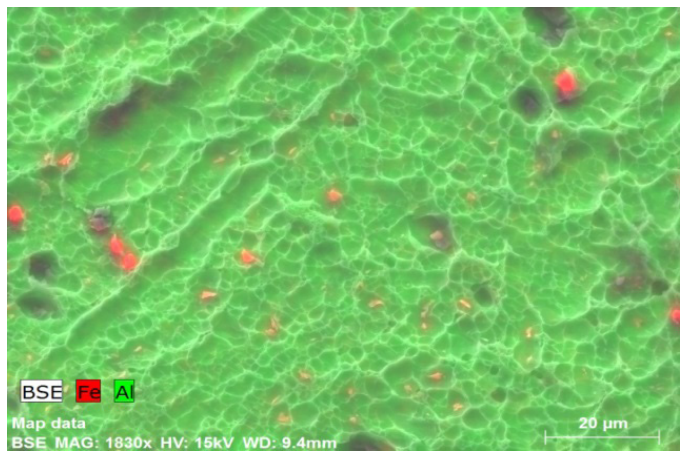

Figura 17. Superfície de fratura do alumínio. Soldas com preaquecimento.

\section{Conclusões}

1)A utilização do preaquecimento por indução eletromagnética na interface aço-alumínio reduziu em $50 \%$ o tempo total de processo;

2)A redução do comprimento nos corpos de prova de alumínio foi maior nas amostras soldadas sem preaquecimento, pois eles ficaram mais tempo expostos ao calor produzido pelo atrito. Isso significa que nas soldas produzidas sem preaquecimento houve mais perda de material para as rebarbas em relação às soldas realizadas com preaquecimento;

3)A maior parcela de deformação no processo de soldagem ocorreu na liga de alumínio, pois ele tem resistência mecânica inferior ao aço. Contudo, nas análises realizadas via microscopia óptica foi possível observar que houve pequena deformação dos grãos de ferrita e perlita do aço próximos à interface de ligação. Nas análises feitas através do microscópio eletrônico de varredura - line scan EDX ficou evidenciado que ocorreu interdifusão entre o ferro e o alumínio, caracterizando o principal mecanismo de ligação na soldagem por friç̧ão, a difusão;

4)Em função dos parâmetros de soldagem utilizados, os perfis de durezas foram semelhantes para as duas condições de soldagem. Em comparação com o metal de base, houve uma redução nos valores de microdureza do alumínio nas regiões periféricas e central da solda. A redução de dureza foi associada ao superenvelhecimento ocorrido na liga de alumínio utilizada. A diminuição de dureza foi maior nas soldas com aquecimento, em percentual essa queda foi da ordem de $5 \%$ maior quando comparada com as soldas sem preaquecimento. Os resultados de microdureza obtidos para o lado do aço em ambas as condições de soldagem foram homogêneos;

5) A ruptura dos corpos de prova ocorreu na interface de ligação para as duas condições de soldagem. Em relação a outros trabalhos da literatura que empregaram a mesma liga de alumínio, a pressão e a velocidade de rotação foram superiores aos adotados nessa pesquisa, o que de certa forma justifica a ruptura ter ocorrido na solda. Outro fator que pode justificar a ruptura na interface de ligação é a possível formação de compostos intermetálicos frágeis. A presença de alumínio na superfície de fratura do aço foi mais evidente nas soldas realizadas sem preaquecimento. Este fato indica que para as soldas sem preaquecimento a ligação entre o alumínio e o ferro foi mais forte em relação às soldas com preaquecimento.

\section{Agradecimentos}

Os autores agradecem ao Laboratório de Robótica Soldagem e Simulação (LRSS) da UFMG onde foram executadas as pesquisas e ao Centro de Desenvolvimento da tecnologia Nuclear (CDTN), nas pessoas dos doutores Tanius Rodrigues Mansur, Luiz Leite da Silva e ao técnico Vlamir Caio Almeida pelo apoio durante as pesquisas. A autora Sheron agradece a CAPES pelo auxílio financeiro. 


\section{Referências}

[1] Sheikhi S, Santos JF. Effect of process parameter on mechanical properties of friction stir welded tailored blanks from aluminum alloy 6181-T4. Science and Technology of Welding and Joining. 2007;12(4):370-375. http://dx.doi.org/10.1179/174329307X173698.

[2] Taban E, Gould JE, Lippold JC. Characterization of 6061-T6 aluminum alloy to AISI 1018 steel interfaces during joining and thermo-mechanical conditioning. Materials Science and Engineering A. 2010;527(7-8):1704-1708. https://doi. org/10.1016/j.msea.2009.10.059 http://dx.doi.org/10.1016/j. msea.2009.10.059.

[3] Sammaiah P, Suresh A, Tagore GRN. Mechanical properties of friction welded 6063 aluminum alloy and austenitic stainless steel. Journal of Materials Science. 2010;45(20):5512-5521. http://dx.doi.org/10.1007/s10853-010-4609-y.

[4] Fukumoto S, Tsubakino H, Okita K, Aritoshi M, Tomita T. Friction welding process of 5052 aluminium alloy to 304 stainless steel. Materials Science and Technology. 1999;15(9):679-686. http:// dx.doi.org/10.1179/026708399101506805.

[5] Pigoretti EV. Junção por difusão da liga Ti-6Al-4V ao aço inoxidável AISI 316 L (tese de doutorado). São Carlos: Universidade Federal de São Carlos; 1999.

[6] Maalekian M. Friction welding - critical assessment of literature. Science and Technology of Welding and Joining. 2007;12(8):738-

\section{9. http://dx.doi.org/10.1179/174329307X249333.}

[7] Kou S. Welding metallurgy. 2nd ed. Hoboken: John Wiley \& Sons; $2003.480 \mathrm{p}$.

[8] Khan IA. Experimental and numerical investigation on the friction welding proces [doctor thesis]. India: Jawaharlal Nehru Technological University; 2011.

[9] Alves EP. Junções de materiais dissimilares utilizando o processo de soldagem por fricção rotativa [tese de doutorado]. São José dos Campos: Instituto Nacional de Pesquisas Espaciais; 2016.

[10] Keat YC, Jamaludin SB, Ahmad ZA. The effect of varying process parameters on the microhardness and microstructure of Cu-steel and Al-Al203 friction joints. Jurnal Teknologi, 2004;41(A):85-95.

[11] American Society for Testing and Materials. ASTM E8M - 04: standard test methods for tension testing of metallic materials [metric]. West Conshohocken: ASTM; 2004.

[12] Monteiro WR. Junção de materiais dissimilares - aço inoxidável AISI 304 - ligas de alumínio para aplicações espaciais [dissertação de mestrado]. São José dos Campos: Instituto Tecnológico de Aeronáutica; 2006.

[13] American Welding Society. AWS: welding handbook. 8th ed. Miami: AWS; 1991. v. 2. 